\title{
Ultrapurification of silicon for photovoltaic applications
}

\author{
Carlos del Cañizo ${ }^{1,2}$ a , Gonzalo del Coso $0^{1, b}$ and Antonio Luque ${ }^{1,2, c}$ \\ ${ }^{1}$ Instituto de Energía Solar, Universidad Politécnica de Madrid, Ciudad Universitaria, Madrid, \\ Spain \\ ${ }^{2}$ Centro de Tecnología del Silicio Solar, Eric Kandel 1, Getafe, Spain \\ acanizo@ies-def.upm.es, 'gdelcoso@ies-def.upm.es, Iuque@ies-def.upm.es
}

Keywords: Silicon feedstock, chlorosilanes, polysilicon.

\begin{abstract}
The recent explosive growth of Photovoltaics and the relative avidity for silicon of the predominant solar cell technology have resulted in a dramatic change of the polysilicon industry structure. While in the past the polysilicon was manufactured almost exclusively for the semiconductor industry, now more than half of the market is devoted to the solar industry. The different alternative routes to purify silicon for photovoltaic applications are presented in the paper, analysing their advantages and drawbacks. Emphasis is made on the CENTESIL initiative, a new private-public partnership venture promoting a pilot plant that is in an advanced state of construction. The goal is to allow the photovoltaic companies worldwide to count with an independent research centre to help them to establish their own polysilicon plant.
\end{abstract}

\section{Introduction}

Being Silicon the workhorse of the current expansion of Photovoltaic (PV) technology, the market for ultrapurified silicon (which is typically called "polysilicon'), that was traditionally devoted to microelectronics, is currently subject to profound changes due to the expansion of the PV market. In 2008 , a total amount $47,700 \mathrm{t}$ of polysilicon were consumed by the solar industry vs 22,300 by the semiconductor industry [1], and the share of polysilicon for solar will for sure increase in the medium and long run, as the perspectives of growth for the PV industry are very solid [2]. The consequence is that while in 2000 virtually only 7 companies supplied all the polysilicon consumed worlwide, now this concentration does not make sense any more, since even for a medium size PV company producing $100 \mathrm{MWp} / \mathrm{a}$, it is worth having their own silicon feedstock factory, in the range of $1000 \mathrm{t} / \mathrm{a}$.

The avidity of polysilicon of the PV companies has made them live a complex situation in the last years, as the traditional suppliers were not prepared to attend their quickly growing demands. That produced an scenario of scarcity of polysilicon, which made prices climb up to the hundred of dollars level, shrinked the capacity expansions already planned by a great number of PV companies, and put into trouble to those which were not able to secure their polysilicon feedstock. Traditional polysilicon suppliers reacted expanding production, and a number of newcomers tried to enter the market, acquiring the technology by themselves or even exploring the viability of new sources of purified silicon [3].

The scenario has abruptly changed due to the economic crisis, the financial restrictions and the modified regulations of some PV regional markets such as Spain. In 2009 the PV companies grew at a much lower rate than expected, so that many requests for polysilicon have been cancelled or postponed, making polysilicon prices quickly go down, strengthening the position of the established companies, as they have optimised cost structures and proven technologies, and putting pressure to the new entrants that have to compete with them.

But this situation of overcapacity is temporary, because PV annual productions in the range of tens of GW are foreseen in some years. The demand for polysilicon will be much higher, and new capacity will have to be implemented. Then, issues such as material quality, energy consumption in the fabrication process and cost structure of the product will come back to the foreground. 
In this paper, the different routes pursued to purify silicon are firstly described, paying attention to the key aspects for PV applications. Then, an initiative to tackle with improvements and innovations in polysilicon technology is presented, highlighting the steps taken in the first stage of the project, its present status and the prospects for the near future.

\section{Routes towards ultrapurified silicon for photovoltaic applications}

Metallurgical silicon is the raw material for polysilicon production. It comes from the carbothermic reduction of quartz at high temperature $\left(2000^{\circ} \mathrm{C}\right.$ approximately) in an electrical arc furnace. The liquid silicon produced is refined in a laddle, poured in mould where it solidifies, and crushed. 98$99 \%$ pure silicon is obtained in a process that consumes around $10 \mathrm{kWh} / \mathrm{kg}$. Annual world production is in the range of 1.500 .000 tonnes per year, of which only a small fraction $(<10 \%)$ is devoted to the semiconductor and photovoltaic industries.

But further purification in these cases is required, for which a three step process known as "Siemens process" is conventionally performed: metallurgical silicon reacts with hydrogen chloride in a fluidized bed reactor to synthesize a volatile compound, thrichlorosilane, which can be fractionally distilled in a number of columns, and then deposited as solid silicon by Chemical Vapor Deposition (CVD) on slim seed rods heated by Joule effect. Purities in the range of $99.9999999 \%$ are within reach, but at the cost of high energy consumption (in the range of $100-150 \mathrm{kWh} / \mathrm{kg}$ ) and low efficiency deposition (for each mole of Si converted to polysilicon in the CVD reactor, 3 to 4 moles are converted to $\mathrm{SiCl}_{4}$ ) [4].

For PV applications, the level of silicon purification is not as stringent as that of the microelectronics case, giving room to process simplifications that can lead to cost reductions. Several routes are pursued to develop a product that can be called "solar silicon". They are classified in Figure 1, and briefly described below. Most of them correspond to routes already explored in the 70s-80s [5][6], which achieved different levels of development but in general did not reached industrial production due to funding cuttings and market conditions.

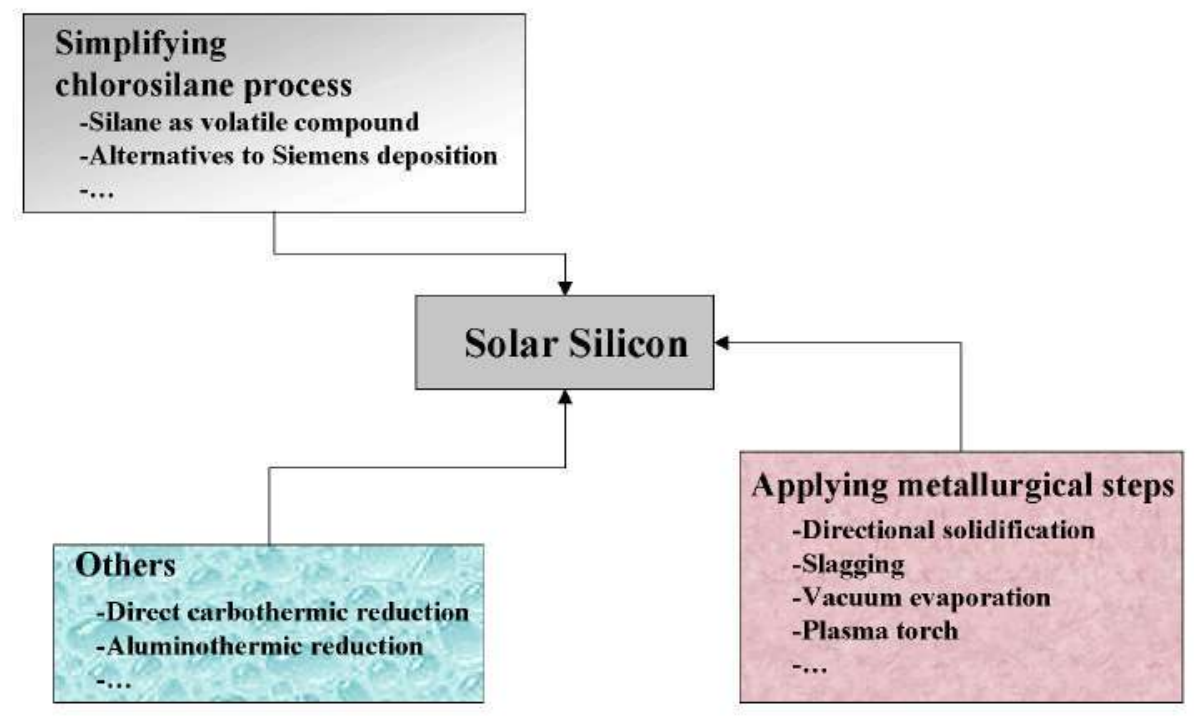

Figure 1. Routes followed to produce "solar silicon".

\section{Simplifying the chlorosilane route}

Trichlorosilane can be replaced by monosilane, which has advantages in the deposition step because deposition temperatures are lower $\left(800^{\circ} \mathrm{C}\right.$ instead of $\left.1100^{\circ} \mathrm{C}\right)$ and productivities can be higher. This process was already proposed in the early 80 s and industrially exploited for the semiconductor industry first and for the solar more recently [7]. The drawback is the need of additional steps for redistribution and separation, as monosilane is produced from triclorosilane, and the need of recycling the chlorosilanes not converted in th redistribution steps. 
Being the silicon deposition in the CVD reactor responsible of a big part in the cost of the technology, another idea is to replace the silicon seed rods by small silicon particles which are continuosly fed into a fluidised bed reactor. This is a continous process and not a batch-type one, increasing the productivity, and avoids the need to crush the deposited silicon. On the other hand, there are some challenges to use these silicon granules in the following crystallisation step that should be addressed.

A combination of silane and fluidised bed deposition is already in production since the 90s [4], and the use of trichlorosilane is being evaluated as an alternative [8].

A different approach called Vapor to Liquid Deposition injects trichlorosilane at a very high temperature into a graphite tube where it first liquifies in droplets and after solidifies in granules. The process is continuous, the energy consumption is reduced and the productivity is increased, but carbon is incorporated to the silicon in great quantities [9]. A concept based on the decomposition of silane to silicon powder in a free-space reactor also aims at reaching high productivity and low energy consumption [10].

In general, the "chlorosilane route" technologies reach high levels of purity, so the question that they should answer is whether they do that at a lower cost than the conventional approach.

\section{Applying typical steps from metallurgical refinement}

The metallurgical route refers to processes that avoid the conversion of metallurgical silicon into a volatile compound, decreasing to a great extent the energy consumption in the deposition step. They try to upgrade the metallurgical silicon through a combination of steps suited for the different impurities. For example, by directional solidification they take advantage of the high liquid-solid segregation coefficient of metallic impurities; by leaching they eliminate metallic silicides in the grain boundaries; by slagging, gas blowing, evaporation and plasma torch they try to reduce the concentration of boron and/or phosphorus;... [11] [12] [13].

The purity usually reached with these processes is much lower than that of the chlorosilane route, but that does not necessarily mean that the material cannot be used for solar cells. In fact, by introducing some changes in the crystallisation and solar cell processing steps, similar solar cell efficiencies have been achieved with this lower quality material than with semiconductor grade one [14].

Another issue that "metallurgical route" technologies should address is the process yield, as a fraction of the material may not reach the required quality. It should be noted that in general terms these technologies are more sensitive to the initial quality of the metallurgical silicon.

\section{Others}

A direct carbothermic reduction from selected quartzs and carbons has also been investigated, with the philosophy to avoid not only the chlorosilanes but also the metallurgical intermediate step [15]. Steps to reduce carbon content should be incorporated, and until now the silicon quality is in the low range.

Other ideas are also raised from time to time, followed some time because of their potential, but abandoned or "frozen" due to poor results or lack of funding,... and sometimes revisited after a while. This is the case of using as volatile compound silicon tetrafluoride, produced from a byproduct of the fertiliser industry [5], performing an aluminothermic reduction of silicon [16], or transferring electrolytically silicon trough a $\mathrm{KF}: \mathrm{LiF}: \mathrm{SiK}_{2} \mathrm{~F}_{6}$ electrolite [17], for instance.

\section{Quality and cost}

Although quality requirements for PV applications are 'relaxed' as compared to those of microelectronics, they are still very demanding, so that there is an open debate about what are the acceptable contamination levels within the purified silicon feedstock to specify the material as solar silicon. Applying a simple model, we have calculated the acceptable contamination levels of different characteristic impurities for each fabrication step of a typical industrial process, from 
feedstock to solar cell [18] [19]. The influence in the impurity dynamics of the gettering step in solar cell processing and the liquid-solid segregation in crystallisation is taken into account, and the aim is to define the impurity concentration allowing to reach a cell efficiency of $15 \%$. The different impurity behaviour in a monocrystalline or a multicrystalline wafer, related to precipitation in defects, is also considered. A summary of the results is shown in Table I, which illustrates that the acceptable contamination level in solar cells depends on the form the polysilicon is crystallised, on the one hand, and on the impurity, being for example almost two orders of magnitude higher for $\mathrm{Fe}$ than for Cr.

This analysis should be complemented with the effect of the dopant levels, which can be allowed in solar grade polysilicon in higher concentrations than in electronic grade one [20]. So, we think that for PV applications, a general specification of purity $(99.999 \%$ or $99,99999 \%$, for example) is not informative enough, and a more detailed one should be made. Also, the purification methods should take this into account, developing dedicated steps for specific impurities, if necessary.

Table I. Acceptable contamination levels of polysilicon for metal impurities with distinct capture cross sections and diffusion coefficients [18] [19].

\begin{tabular}{|c|c|c|c|}
\hline Element & $\begin{array}{c}\text { Reference for } \\
\text { semiconductor } \\
\text { polysilicon [ppma] }\end{array}$ & $\begin{array}{c}\text { Concentration in the } \\
\text { polysilicon for } a \\
\text { monocrystalline solar cell } \\
\text { [ppma] }\end{array}$ & $\begin{array}{c}\text { Concentration in the } \\
\text { polysilicon for } a \\
\text { multicrystalline solar cell } \\
\text { [ppma] }\end{array}$ \\
\hline $\mathrm{Ti}$ & $<0.003$ & 0.0002 & 0.022 \\
\hline $\mathrm{Cr}$ & $<0.003$ & 0.18 & 0.026 \\
\hline $\mathrm{Fe}$ & $<0.01$ & 9.4 & 12.5 \\
\hline $\mathrm{Cu}$ & $<0.003$ & 8.4 & 4.6 \\
\hline
\end{tabular}

As a trade-off between process cost and material quality exists, a threshold for low cost routes should be established to preserve a certain quality level. To account for that, we have performed a cost analysis within CrystalClear, a European integrated project carried out in the $6^{\text {th }}$ Framework Programme. A crystalline Si reference technology is analysed, whose cost structure is based on direct manufacturing cost data provided by industrial partners. Cost savings due to large scale production of several hundred $\mathrm{MWp} / \mathrm{a}$ are estimated, and the impact of new silicon feedstock materials on the total module cost is quantified by describing the new materials in terms of cost $(€ / \mathrm{kg})$ and quality (evaluated as cell efficiency) [21].

Iso-cost curves can then be drawn, helping to extract interesting conclusions (see Figure 2). For instance, the steep lines show that the technology is relatively insensitive to feedstock cost increases: coming from the situation of $20 \mathrm{E} / \mathrm{kg}$ and relative efficiency 1 , if the feedstock cost increases to $30 \mathrm{E} / \mathrm{kg}$ ( $50 \% \mathrm{up}$ ), increasing efficiency by a relative $6 \%$ neutralises the cost increase, and the module cost remains constant. Likewise, if the efficiency decreases a relative $10 \%$, the feedstock cost should decrease to $2 € / \mathrm{kg}$ ( $90 \%$ down) to keep the module cost constant.

In our opinion, this is an important argument supporting the option of high purity material: high efficiency is a key driver for cost reduction, and the feedstock cost increase can be easily compensated by high efficiencies. That is why the initiative CENTESIL, which is presented in the next section, is aligned with the production of highly purified polysilicon for high efficiency solar cells via the chlorosilane route. 


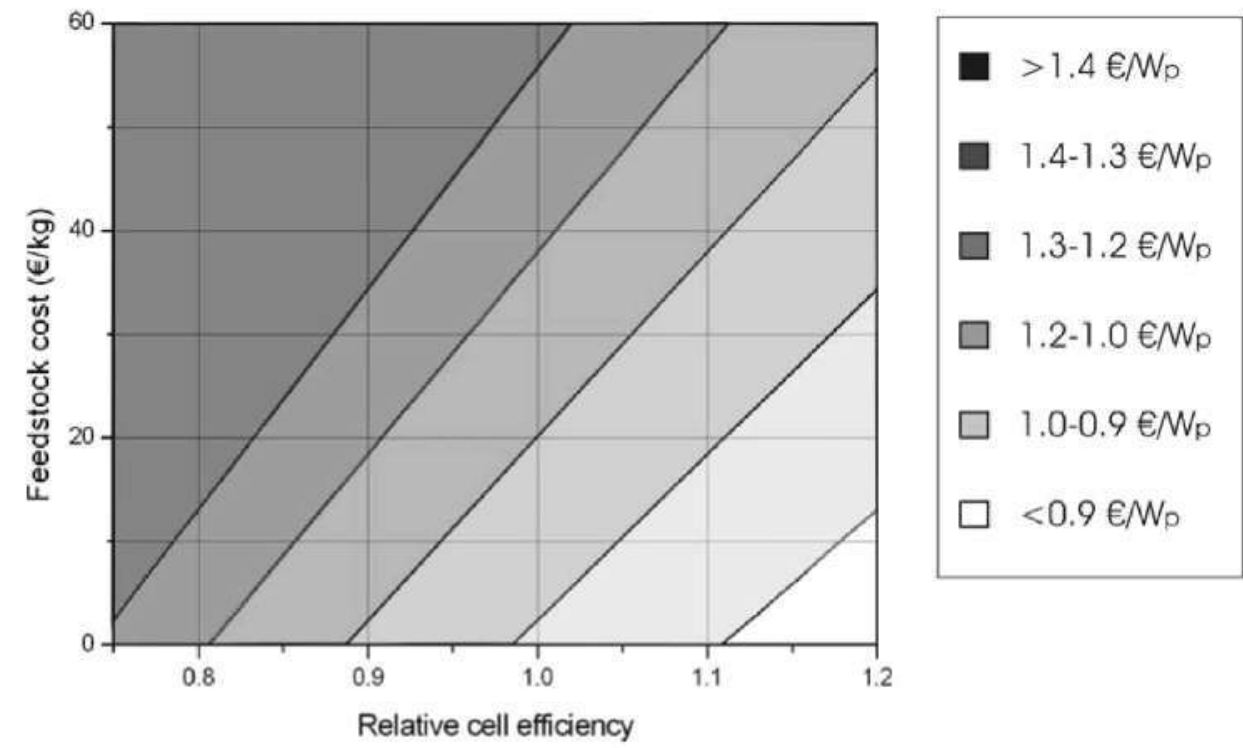

Figure 2. Iso-cost curves for a reference technology regarding cell efficiency and feedstock cost [21]. The relative cell efficiency is the ratio of the cell efficiency achieved with a new material and the cell efficiency achieved with the conventional electronic material.

\section{Centesil, R\&D on polysilicon deposition}

Centro de Tecnología del Silicio Solar, CENTESIL, was founded in 2006 as a private-public partnership venture owned by Universidad Politécnica de Madrid (29.5\% of the shares), Universidad Complutense de Madrid (19.5\%), and three companies (Isofotón, DCWafers and Técnicas Reunidas, each with $17 \%$ ). At the moment it is a Spanish initiative, but it has the clear vocation of opening to an international partnership.

CENTESIL is currently building a $100 \mathrm{t} / \mathrm{a}$ pilot plant for silicon purification following the chlorosilane route. Although a classical modernized technological path has been selected as first choice, the purpose is to be able to undertake developments in any topic that has the potential to reduce the cost effectively.

The development contains four areas of activity: (1) synthesis of chlorosilanes, with the silicon tetrachloride, a process by-product, as the main source of chlorine; (2) chlorosilane purification based on fractional distillation but with additional processes when necessary to remove lifetimekilling impurities; (3) development of routes to reduce the energy consumption of the chemical vapor deposition and (4) recycling of the by-products for optimal use and sustainability.

Additionally, the project includes facilities for monocrystalline growth and wafering, and also the solar cell processing line of the Instituto de Energía Solar, so that it will benefit from an integrated approach, from feedstock to solar cell.

The plant is placed in a technological park in Getafe, a village south of Madrid, where a building of $2500 \mathrm{~m}^{2}$ has been constructed, of which $2000 \mathrm{~m}^{2}$ are devoted to technological infrastructures and the rest is for offices, meeting rooms, corridors, etc.

Some of the steps taken to define the pilot plant are briefly described now. They cover modeling, experimental developments at the laboratory level and design and engineering of the pilot plant.

At CENTESIL we performed an analysis of alternatives for chlorination, and decided to produce trichlorosilane (TCS) in a fluidized bed reactor from metallurgical silicon, hydrogen and silicon tetrachloride (STC) [22]. Working at higher temperatures and pressures as compared to the traditional fluidized bed reactor fed with metallurgical silicon and $\mathrm{HCl}$, it has a great cost reduction potential mainly because it avoids the need of conversion of the STC produced as a by-product in the CVD reactor. Nevertheless, the plant will also include a fixed bed reactor for Si hidroclorination 
to consume the hydrogen chloride of the CVD reactor effluent and to give flexibility to the installation, as well as hydrogen purification devices.

The fluid dynamic conditions required to deposit polysilicon in the CVD reactor have also been modeled, analyzing the dependence of the growth rate, deposition efficiency, and power loss on some relevant variables such as the gas velocity, the mixture of gas composition the rod surface temperature, etc. [23]. This modeling has been combined with an analysis of the radiative energy loss for several reactor configurations, aiming at diminishing it [24]. A couple of examples of the modeling activities are shown in Figure 3.

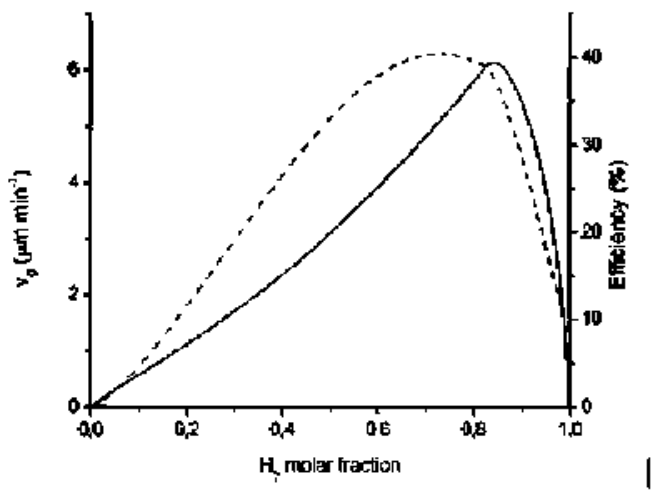

(a)

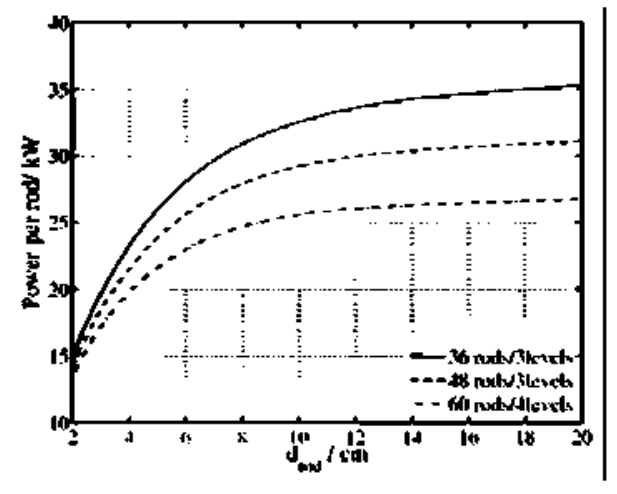

(b)

Figure 3. Example of results from the model of CVD deposition. (a) Growth velocity ( - ) and deposition efficiency (-- ) as a function of molar fraction $\mathrm{H}_{2}:$ TCS. (b) Average power emitted per rod and absorbed by the reactor wall for different reactor configurations.

Laboratory prototypes have been constructed to gain knowledge on the process, in particular a fixed bed reactor for the synthesis of chlorosilanes, and a one seed-rod polysilicon reactor to validate the information obtained through the aforementioned model. They have helped in the design of the industrial reactors for the pilot plant.

The conceptual design and detailed design of the pilot plant have been developed, following the sketch of Figure 4. P\&ID, material balances and equipment specifications have been established for the different areas shown in the graph.

Purchases of the different pieces of equipment are now taking place, and their installation is now being developed. The whole installation is planned to be ready by the end of 2010 .

The experience already gained in designing the pilot plant has allowed us to make a first estimate of the cost breakdown for an industrial plant. For instance, with the technology we can recommend today we think an investment of $81 € / \mathrm{kg}$ is required, of which around $60 \% \mathrm{~s}$ correspond to the deposition area. The operational cost for the polysilicon producer can be $26 \mathrm{E} / \mathrm{kg}$ if the cost of the electricity is $0.08 \mathrm{E} / \mathrm{kWh}$ and the plant size $3000 \mathrm{t} / \mathrm{year}$. But we have also identified which are the main cost components to focus future research on them. We believe that the polysilicon cost can be more than halved while keeping a quality that would permit manufacturing high efficiency cells.

In this moment CENTESIL has already a technology to recommend to potential customers. It knows its approximate cost and where further R\&D might reduce it substantially. 


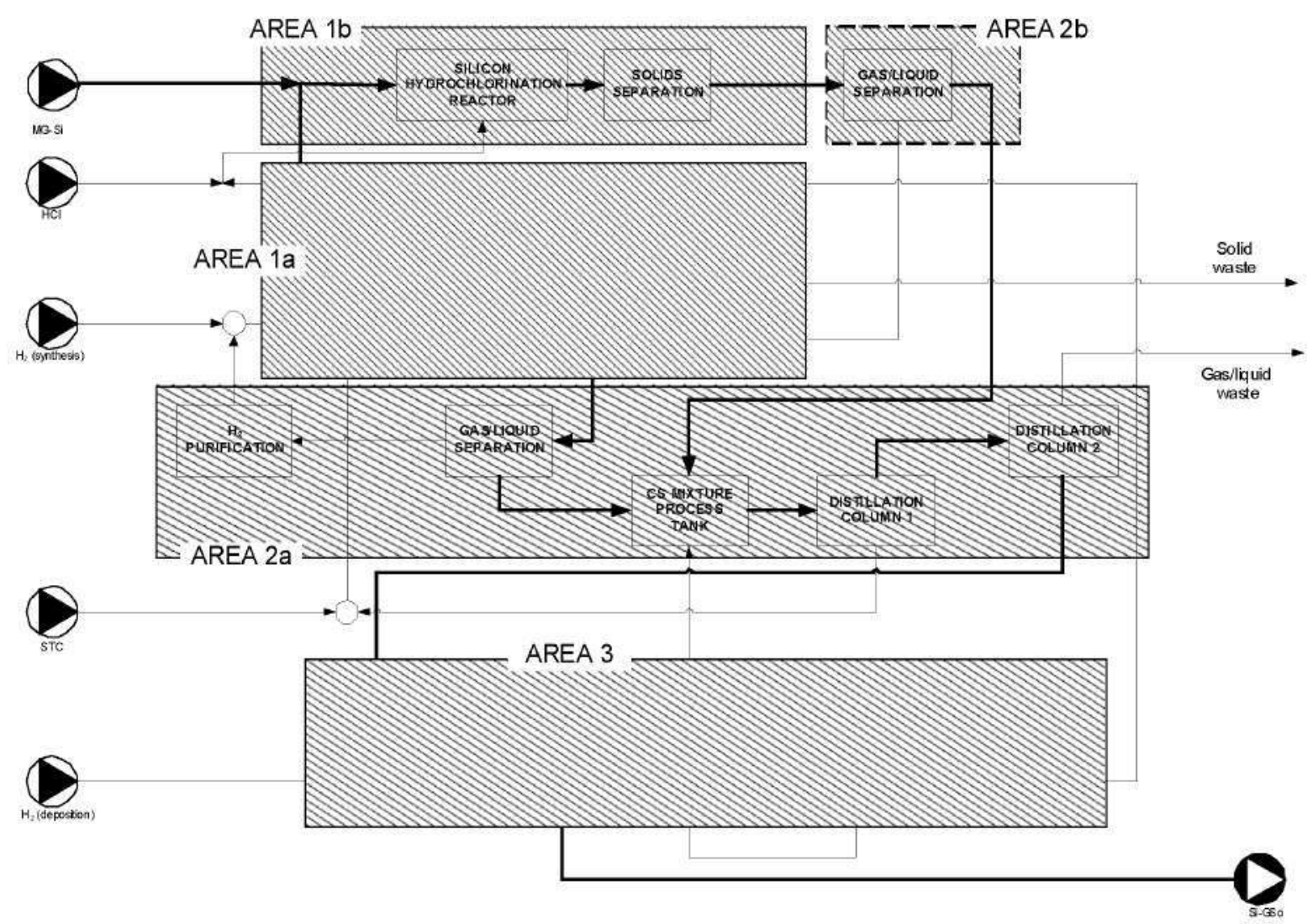

Figure 4. Sketch of the pilot plant, showing the different technologycal areas: synthesis of chlorosilanes (areas $1 \mathrm{a} \& \mathrm{~b}$ ), distillation (areas $2 \mathrm{a}$ and $2 \mathrm{~b}$ ), and Si deposition and recirculation of the reactor effluents (area 3 ).

\section{Summary}

CENTESIL is an initiative to build an R\&D pilot plant for polysilicon purification adapted to photovoltaic applications. It has started with a classical modernised technology that involves four basic steps: (1) hidrochlorination of metallurgical silicon; (2) purification by fractional distillation among other procedures; (3) reduction in a CVD reactor of low electric consumption; and (4) reconditioning of the effluents tending towards a closed cycle process. In the future and as far as improvements are invented, modifications will be incorporated to this process.

To our knowledge, this is the only research centre worldwide developing polysilicon at the pilot plant scale that is not linked to a polysilicon manufacturer. CENTESIL is to become a commercial technology provider of polysilicon technology, and also to license to third parties worldwide the manufacturing of the equipments developed.

\section{Acknowledgements}

The Spanish Ministerio de Ciencia e Innovación and the Fondo Europeo de Desarrollo Regional are greatly acknowledged for their support through projects PSE-120000-2007-3 and PEN-1200002009-35.

\section{References}

[1] W.P. Hirshman, Photon International Vol. 3 (2009), p. 82.

[2] A. Luque, Progress in Photovoltaics Vol. 9 (2001), p. 303.

[3] M. Mayers, Photon International Vol. 8 (2009), p. 82. 
[4] B. Ceccaroli in Handbook of Photovoltaic Science and Engineering, edited by A. Luque and S. Hegedus, chapter 5, John Wiley \& Suns, West Sussex (2003).

[5] JR. McCormick in Silicon Processing for Photovoltaics I, edited by CP. Khattak and KV. Ravi, chapter 1, Elsevier Science Publishers (1985).

[6] J. Dietl in Silicon Processing for Photovoltaics II, edited by CP. Khattak and KV. Ravi, chapter 6, Elsevier Science Publishers (1987).

[7] G. Bye, presented at 3rd Solar Silicon Conference, Munich (2006).

[8] D. Weidhaus, E. Schindlbeck, K. Hesse, E. Dornberger, Proc. 20th European Photov. Solar Ener. Conf., WIP Renewable Energies (2005), p. 565.

[9] H. Oda, presented at 1st Solar Silicon Conference, Munich (2004).

[10] A. Müller, R. Sonnenschein, T. Sill, A. Gölz, C. Beyer, J. Piotraschke, D. Kaden, D. Bednarek and S. Stute, Proc. 24th European Photov. Solar Ener. Conf., WIP Renewable Energies (2009), p. 1406.

[11] N. Yuge, M. Abe, K. Hanazawa, H. Baba, N. Nakamura, Y, Kato, Y. Sakaguchi, S. Hiwasa, F. Aratani, Progress in Photovoltaics Vol. 9 (2001), p. 203.

[12] G. Flamanta, V. Kurtcuoglub, J. Murraya, A. Steinfeld, Solar Energy Mat. \& Solar Cells Vol. 90 (2006) p. 2099.

[13] S. Rousseau, M. Benmansour, D. Morvan, J. Amouroux, Solar Energy Mat. \& Solar Cells Vol. 91 (2007) p. 1906.

[14] K. Peter, R. Kopecek, A. Soiland, E. Enebakk, Proc. $23^{\text {rd }}$ European Photov. Solar Ener. Conf., WIP Renewable Energies (2008), p. 947.

[15] E. Ovrelid, B. Geerligs, A. Wærnes, O. Raaness, I. Solheim, R. Jensen, K. Tang, S. Santeen, B. Wiersma, Proc. Silicon for the Chemical Industry VIII, Norwegian University of Science and Technology, Trodheim (2006), p. 223.

[16] BN. Mukashev, KhA.Abdullin, MF.Tamendarov, TS.Turmagambetov, BA.Beketov, MR. Page, DM. Kline, Solar Energy Mat. \& Solar Cells Vol. 93 (2009) p. 1785.

[17] K. Carleton, J. Olson, A. Kibbler, J. Electrochem. Soc. Vol 130 (1983) p.782.

[18] C. del Cañizo, A. Luque, J. Bullón, Á. Miranda, JM. Miguez, H. Riemann, N. Abrosimov, Proc. $20^{\text {th }}$ European Photov. Solar Ener. Conf., WIP Renewable Energies (2005), p. 946.

[19] J. Hofstetter, J.F. Lelièvre, C. del Cañizo, A. Luque, Mater. Science \& Engin. B, Vol. 159-160 (2009), p. 299.

[20] S. Dubois, N. Enjalbert, J.P. Garandet, Appl. Phys. Let. Vol. 93 (2008) p. 32114.

[21] G. del Coso, C. del Cañizo, W. Sinke, Solar Energy Mat. \& Solar Cells Vol 94 (2010), p. 345.

[22] L. Méndez, PhD. Thesis, Universidad Complutense de Madrid, Madrid, 2009.

[23] G. del Coso, C. del Cañizo, A. Luque, J. Electrochem. Soc. Vol. 155(6) (2008), p. 489.

[24] G. del Coso, C. del Cañizo, A. Luque: Radiative energy loss in a polysilicon CVD reactor, submitted for publication (2010). 